\title{
COMPARISON OF OPTIMIZATION TECHNIQUES OF INPUT PARAMETERS IN WIRE ELECTRICAL DISCHARGE MACHINING
}

\author{
Avinash K ${ }^{1}$, R Rajashekar ${ }^{2} \&$ B M Rajaprakash ${ }^{3}$
}

Abstract -Wire EDM is a non-traditional machining method primarily used for machining hard metals or those that would be impossible to machine with traditional techniques. The non-contact machining technique has been continuously evolving from a mere tool and dies making process to a micro-scale application. In this research paper, the machining of High Speed Steel (HSS) material using Wire Electric Discharge Machining (WEDM) with Brass as a wire electrode has been carried out. The pulse on time, pulse off time and servo voltage were selected as control process parameters of Wire EDM. Both Taguchi and Response Surface Method (RSM) techniques were applied to determine optimized process parameter to maximize Material Removal Rate (MRR) and minimize Surface Roughness (Ra). These techniques were compared based on time, trials and cost concern. The effect of process parameters on MRR and Ra was found by using Analysis of Variance (ANOVA)

Keywords - Wire Electric Discharge Machining (WEDM), Material Removal Rate (MRR), Surface Roughness (Ra), Taguchi method, Response Surface Method (RSM), HSS material.

\section{INTRODUCTION}

Wire EDM (Electric Discharge Machining) is a thermo electrical process in which material is eroded by a series of sparks between the work piece and the wire electrode (tool). The part and wire are immersed in a dielectric (electrically nonconducting) fluid which also acts as a coolant and flushes away debris. The movement of wire is controlled numerically to achieve the desired three dimensional shapes, surface finish and high accuracy of the work piece. In this process, there is no contact between work piece and electrode, thus materials of any hardness can be cut as long as they can conduct electricity. Whereas the wire does not touch the workpiece, so there is no physical pressure imparted on the workpiece and the amount of clamping pressure required to hold the workpiece is minimal. Although electrical conductivity is an important factor in this type of machining, some techniques can be used to increase the efficiency in machining of low electrical conductive materials. The heat of each electrical spark, estimated at around $15,000^{\circ}$ to $21,000^{\circ}$ Fahrenheit, at this temperature erosion of workpiece takes place and hence cutting can be achieved by moving wire or base on which work is mounted in desired work path. This process has been widely used in aerospace, nuclear and automotive industries, to machine precise, complex and irregular shapes in various difficult to machine electrically conductive materials. Wire EDM process is also being used to machine a wide variety of miniature and micro-parts made of metals, alloys, sintered materials, cemented carbides, ceramics and silicon. These characteristics makes Wire EDM a process which has remained as a competitive and economical machining option fulfilling the demanding machining requirements imposed by the short product development cycles and the growing cost pressures. The working principle is shown in Figure 1.

The most important performance measures in Wire EDM are Metal Removal Rate (MRR) and Surface Roughness (Ra). They depend on machining parameters or process parameter or input parameter like discharge current, pulse on time, pulse off time, wire speed, wire tension, servo voltage and dielectric flow rate.

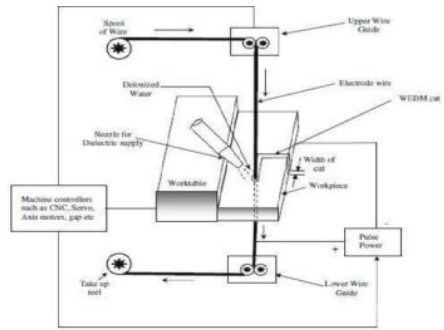

Figure 1 Schematic diagram of working principle of Wire EDM

\footnotetext{
${ }^{1}$ Research scholar, Department of Mechanical Engineering, University Visvesvaraya College of Engineering, Bangalore University, $K R$ circle Bengaluru, Karnataka, India - 560001

${ }^{2}$ Assistance Professor, Department of mechanical engineering, University Visvesvaraya College of Engineering, Bangalore University, $K R$ circle Bengaluru, Karnataka, India - 560001

${ }^{3}$ Professor and Chairman, Department of mechanical engineering, University Visvesvaraya College of Engineering, Bangalore University, $K R$ circle Bengaluru, Karnataka, India - 560001
} 
Among these machining parameters, Pulse on time, pulse off time and servo voltage have been considered for experimental purpose, as they are the most significant control factors for both maximization of MRR and minimization of Ra (Performance parameter or output parameter). Process parameters are generally controllable machining input factors that determine the conditions in which machining is carried out. These machining conditions will affect the process performance result, which are gauged using various performance measures.

In setting the machining parameters to obtain maximum MRR and minimum Ra, generally the machine tool builder provides machining parameter table. This process relies heavily on the experience of the operators. In practice, it makes very difficult to utilize the optimal functions of a machine owing there are too many adjustable machining parameters. To solve this difficulty, a simple but reliable method based on statistically designed experiments is suggested for investigating the effects of various process parameters on MRR and Ra and determine optimal process settings. There are several optimizing techniques available and among them Taguchi technique and Response Surface Methodology are very efficient, powerful experimental design tools which uses simple, effective and systematic approach for deriving of the optimal machining parameters.

In the present work, both Taguchi method and Response Surface Method (RSM) were applied to determine optimized process parameter to maximize Material Removal Rate (MRR) and minimize surface roughness (Ra). Taguchi technique and RSM have been compared based on the time consumed, cost of operation and number of trials.

\section{METHODOLOGY}

A. Machine specification and material

The experiments were carried out on a Wire EDM machine (ECOCUT WEDM) to measure MRR value and Mituttoyo Surface Roghness Tester was used to measure Ra value.

The Wire EDM machine tool has following specifications:

- X Axis Table Travel : $250 \mathrm{~mm}$

- Y Axis Table Travel $\quad: 350 \mathrm{~mm}$

- Z Axis Travel : $200 \mathrm{~mm}$

- Max. work piece size : 575 X 835 X $200 \mathrm{~mm}$

- Max. Work piece wt. : $275 \mathrm{Kg}$

- Main table feed rate $: 80 \mathrm{~mm} / \mathrm{min}$

- Wire feed rate $\quad: 0-10 \mathrm{~m} / \mathrm{min}$

- Wire guide type : Diamond closed

- Wire electrode diameter : $0.25 \mathrm{~mm}$ STD, $0.2 \mathrm{~mm}$ optional

- Input voltage $\quad: 310 \mathrm{~V}$ to $467 \mathrm{~V}$ line to line. i.e. 180 -- $270 \mathrm{~V} /$ phase

- Output voltage $\quad: 415 \mathrm{~V}$ line to linei.e. $240 \mathrm{~V}$ phase to neutral

- Voltage correction rate $: 35 \mathrm{~V} / \mathrm{sec}$

- The de-ionized water is used as dielectric: The Mituttoyo Surface Roghness Tester has following specifications

- Measurement range : $350 \mu \mathrm{m}(-200 \mu \mathrm{m}$ to $+150 \mu \mathrm{m})$

- Power system :2 Way (AC adaptor/rechargeable built in battery).

- The sensor movement given to indenter: $4 \mathrm{~mm}$

High Speed Steel (HSS) is used as work piece material for the present work due to the reason that HSS cannot be easily machinable by conventional machining techniques as it has high hardness, also it is an important tool material being used in industries. Chemical composition of HSS material is represented in Table 1.

Table 1 Composition of the material

\begin{tabular}{|l|l|l|l|l|l|l|l|l|}
\hline Constituents & $\mathrm{C}$ & $\mathrm{Si}$ & $\mathrm{Ma}$ & $\mathrm{P}$ & $\mathrm{S}$ & $\mathrm{Cr}$ & $\mathrm{Mo}$ & $\mathrm{Ni}$ \\
\hline \% Comp & 1.364 & 1.9616 & 0.456 & 0.052 & 0.046 & 1.921 & 0.127 & 0.065 \\
\hline
\end{tabular}

B. Optimization techniques

1. Response Surface Methodology (RSM)

Response surface methodology (RSM) is a collection of mathematical and statistical techniques for empirical model building. By careful design of experiments, the objective is to optimize a response (output variable/performance parameter) which is influenced by several independent variables (input/process parameter). The problem can be approximated as described in smooth functions that improve the convergence of the optimization process because they reduce the effects of noise and they allow for the use of derivative based algorithms.

In this method if the response is well modeled by a linear function of the independent variables, then the approximating function as per the First order model is,

$\mathrm{Y}_{\mathrm{U}}=\mathrm{b}_{0}+\mathrm{b}_{1} \mathrm{X}_{1}+\mathrm{b}_{2} \mathrm{X}_{2}+\ldots .+\mathrm{b}_{\mathrm{i}} \mathrm{X}_{\mathrm{i}}+\mathrm{e}$ 
If there is curvature in the system, then a polynomial of higher degree must be used and the corresponding second order model is,

$\mathrm{Y}_{\mathrm{U}}=\mathrm{b}_{0}+\sum_{\mathrm{i}=1}^{K} b_{\mathrm{i}} X_{\mathrm{i}}+\sum_{\mathrm{i}=1}^{K} b_{\mathrm{ii}} X_{\mathrm{i}}^{2}+\sum_{j>\mathrm{i}}^{K} b_{\mathrm{i} j} X_{\mathrm{i}} X_{j}+\ldots+\mathrm{e}$

Where ' $i$ ' is the linear coefficient, ' $j$ ' is the quadratic coefficient, ' $\beta$ ' is the regression coefficient, ' $k$ ' is the number of studied and optimized factors in the experiment and ' $\mathrm{e}$ ' is the random error. Analysis of variance (ANOVA) has taken into account in order to estimate the suitability of the regression model.

\section{Taguchi techniques}

Genichi Taguchi, a Japanese scientist, developed a technique. This technique has been widely used in different fields of engineering to optimize the process parameters. The integration of Design Of Experiment (DOE) with parametric optimization of process can be achieved in the Taguchi method. Taguchi's Signal-to-Noise ratios, (S/N ratios) which are logarithmic functions of the desired output, serve as objective functions for optimization. It helps to learn the whole parameter space with a small number (minimum experimental runs) of experiments. $\mathrm{S} / \mathrm{N}$ ratios are used to study the effects of control factors and noise factors and to determine the best quality characteristics for particular applications. The optimal process parameters obtained from the Taguchi method are insensitive to the variation of environmental conditions and other noise factors. However, originally, Taguchi method was designed to optimize single-performance characteristics. Optimization of multiple performance characteristics is not straightforward and much more complicated than that of single performance characteristics. The experimental observations are further transformed into a signal-to-noise $(\mathrm{S} / \mathrm{N})$ ratio. There are several $\mathrm{S} / \mathrm{N}$ ratios available depending on the type of characteristics. The characteristic that higher value represents better machining performance, such as MRR, is called higher is better (HB). Inversely, the characteristic that lower value represents better machining performance, such as surface roughness, is called lower is better (LB). Therefore, 'HB' for the MRR and 'LB' for the Ra were considered for obtaining optimum input process parameter.

The loss function (L) for objective of HB and LB is defined as follows:

$\mathrm{L}_{\mathrm{HB}}=\frac{1}{n} \sum_{\mathrm{i}=1}^{n} \frac{1}{y_{\text {MRR }}^{2}}$

$\mathrm{L}_{\mathrm{LB}}=\frac{1}{n} \sum_{\mathrm{i}=1}^{\mathrm{n}} y_{\mathrm{Na}}^{2}$

Where ' $y_{M R R}$ ', and ' $y_{R a}$ ' are response for material removal rate and surface roughness, and ' $n$ ' denotes the experiment number. The $\mathrm{S} / \mathrm{N}$ ratio can be calculated as a logarithmic transformation of the loss function as,

$\mathrm{S} / \mathrm{N}$ ratio for $\mathrm{MRR}=-10 \log _{10}\left(\mathrm{~L}_{\mathrm{HB}}\right)$

$\mathrm{S} / \mathrm{N}$ ratio for $\mathrm{Ra}=-10 \log _{10}\left(\mathrm{~L}_{\mathrm{LB}}\right)$

\section{EXPERIMENTATION}

A. Selection of process parameters and their levels

Among all process parameters three parameters such as pulse on time $\left(\mathrm{T}_{\mathrm{ON}}\right)$, pulse off time $\left(\mathrm{T}_{\mathrm{OFF}}\right)$ and servo voltage $(\mathrm{SV})$ are varied during experimentation in three levels, the range of which are found by trial and error method. Table 2 shows parameters selected and their levels. Apart from these parameters there are also other parameters and factors which also have significant effect on performance parameters which are shown in Table 3. They are kept constant to minimize their effects

Table 2 Levels of process parameters

\begin{tabular}{|c|c|c|c|}
\hline \multirow{2}{*}{ Process parameter } & \multicolumn{3}{|c|}{ Levels } \\
\cline { 2 - 4 } & Level 1 & Level 2 & 120 \\
\hline $\mathrm{T}_{\mathrm{ON}}(\mu \mathrm{s})$ & 110 & 115 & 50 \\
\hline $\mathrm{T}_{\mathrm{OFF}}(\mu \mathrm{s})$ & 30 & 40 & 25 \\
\hline $\mathrm{SV}(\mathrm{V})$ & 15 & 20 & Level 3 \\
\hline
\end{tabular}

Table 3 Values of process parameters maintained constant

\begin{tabular}{|c|c|c|c|c|}
\hline Name of parameters & Value & & \multicolumn{2}{|c|}{ Fixed parameters } \\
\hline Peak current & $12 \mathrm{amps}$ & & Wire & $0.25 \mathrm{~mm}$ dia of Brass \\
\hline Wire feed & $7 \mathrm{~m} / \mathrm{min}$ & & Shape of workpiece & Rectangular \\
\hline Wire tension & $7 \mu \mathrm{N}$ & & Thickness of workpiece & $6 \mathrm{~mm}$ \\
\hline Servo feed & $2100 \mathrm{~mm} / \mathrm{min}$ & & Work height & $8 \mathrm{~mm}$ \\
\hline
\end{tabular}

\section{B. Experimental design using Taguchi's technique}

An L9 orthogonal array based on Taguchi's analysis used to specify the experiments are shown in Table 4. The L9 array chosen, has 9 rows corresponding to the number of experiments with 3 columns of process parameters at three levels. The experiments were conducted for each combination of factors as per L9 array. The number of observation made for each combination of factors is 5 during measurement of MRR and is 1 during measurement of Ra. Average value of replication is considered for calculation. In ECOCUT Wire EDM machine MRR is found by using equation below: 
MRR= Cutting speed $\mathbf{x}$ work height

Where 'cutting speed' was measured during each trial

The experimental measured value of MRR and Ra their S/N ratios, calculated using equation (5) and (6) respectively are presented in Table 4.

Table 4: L9 orthogonal array, experimental results and $\mathrm{S} / \mathrm{N}$ ratios

\begin{tabular}{|l|l|l|l|l|l|l|l|}
\hline $\begin{array}{l}\text { Trial } \\
\text { no }\end{array}$ & $\begin{array}{l}\mathrm{T}_{\text {on }} \\
(\mu \mathrm{s})\end{array}$ & $\begin{array}{l}\mathrm{T}_{\text {off }} \\
(\mu \mathrm{s})\end{array}$ & $\begin{array}{l}\mathrm{SV} \\
(\mathrm{V})\end{array}$ & $\begin{array}{l}\text { MRR } \\
\left(\mathrm{mm}^{2} / \mathrm{min}\right)\end{array}$ & $\begin{array}{l}\text { Surface } \\
\text { Roughness } \\
\text { Ra }(\mu \mathrm{m})\end{array}$ & $\begin{array}{l}\text { S/N ratio of } \\
\text { MRR }\end{array}$ & $\begin{array}{l}\text { S/N ratio of } \\
\text { RA }\end{array}$ \\
\hline 1 & 105 & 30 & 15 & 13.76 & 2.152 & 22.7724 & -6.65685 \\
\hline 2 & 105 & 40 & 20 & 13.04 & 1.780 & 22.3056 & -5.00840 \\
\hline 3 & 105 & 50 & 25 & 5.92 & 1.623 & 15.4464 & -4.20637 \\
\hline 4 & 110 & 30 & 20 & 23.5216 & 2.290 & 27.4293 & -7.19671 \\
\hline 5 & 110 & 40 & 25 & 17 & 2.225 & 24.6090 & -6.94660 \\
\hline 6 & 110 & 50 & 15 & 10.34 & 2.123 & 20.2904 & -6.53900 \\
\hline 7 & 115 & 30 & 25 & 25.8864 & 2.162 & 28.2614 & -6.69711 \\
\hline 8 & 115 & 40 & 15 & 29.04 & 2.572 & 29.2599 & -8.20542 \\
\hline 9 & 115 & 50 & 20 & 14.3832 & 2.036 & 23.1571 & -6.17556 \\
\hline
\end{tabular}

C. Experimental design using Response Surface Methodology (RSM)

In RSM L20 orthogonal array was chosen. It consists of 20 rows corresponding to the number of experiments with three columns of process parameters. Here same selected process parameters for same three levels as used in Taguchi's technique are varied. Face centered central composite design was adopted to design the experiments as shown in Table 5. RSM was used to develop second order regression equation which gives relation between process parameters $\left(\mathrm{T}_{\mathrm{ON}}, \mathrm{T}_{\mathrm{OFF}}\right.$ and $\left.\mathrm{SV}\right)$ and performance parameters (MRR or Ra).

Table 5: L20 orthogonal array and experimental results for RSM

\begin{tabular}{|l|l|l|l|l|l|l|l|}
\hline $\begin{array}{l}\mathrm{S} 1 \\
\text { no }\end{array}$ & $\begin{array}{l}\mathrm{T}_{\mathrm{ON}} \\
(\mu \mathrm{s})\end{array}$ & $\begin{array}{l}\mathrm{T}_{\text {OFF }} \\
(\mu \mathrm{s})\end{array}$ & $\begin{array}{l}\mathrm{SV} \\
(\mathrm{V})\end{array}$ & $\begin{array}{l}\text { Cutting } \\
\text { speed } \\
(\mathrm{mm} / \mathrm{min})\end{array}$ & $\begin{array}{l}\text { Work } \\
\text { height } \\
(\mathrm{mm})\end{array}$ & $\begin{array}{l}\text { MRR } \\
\left(\mathrm{mm}^{2} / \mathrm{min}\right)\end{array}$ & $\begin{array}{l}\text { Surface } \\
\text { roughness } \\
\text { Ra }(\mu \mathrm{m})\end{array}$ \\
\hline 1 & 105 & 30 & 15 & 1.72 & 8 & 13.76 & 2.152 \\
\hline 2 & 115 & 50 & 15 & 2.0599 & 8 & 16.4792 & 2.360 \\
\hline 3 & 115 & 30 & 25 & 3.2358 & 8 & 25.8864 & 2.162 \\
\hline 4 & 105 & 50 & 25 & 0.74 & 8 & 5.92 & 1.623 \\
\hline 5 & 110 & 40 & 20 & 2.3103 & 8 & 18.4824 & 2.288 \\
\hline 6 & 110 & 40 & 20 & 2.3103 & 8 & 18.4824 & 2.288 \\
\hline 7 & 115 & 30 & 15 & 3.77 & 8 & 30.16 & 2.7388 \\
\hline 8 & 105 & 50 & 15 & 0.9142 & 8 & 7.3136 & 1.751 \\
\hline 9 & 105 & 30 & 25 & 1.4012 & 8 & 17.216 & 1.929 \\
\hline 10 & 115 & 50 & 25 & 1.57 & 8 & 12.56 & 1.845 \\
\hline 11 & 110 & 40 & 20 & 2.3103 & 8 & 18.4529 & 2.288 \\
\hline 12 & 110 & 40 & 20 & 2.3103 & 8 & 18.4529 & 2.288 \\
\hline 13 & 105 & 40 & 20 & 1.63 & 8 & 13.04 & 1.780 \\
\hline 14 & 115 & 40 & 20 & 3.5360 & 8 & 28.288 & 2.496 \\
\hline 15 & 110 & 30 & 20 & 2.9402 & 8 & 23.5216 & 2.296 \\
\hline 16 & 110 & 50 & 20 & 1.1287 & 8 & 9.0296 & 2.085 \\
\hline 17 & 110 & 40 & 15 & 2.5543 & 8 & 20.4344 & 2.339 \\
\hline 18 & 110 & 40 & 25 & 2.125 & 8 & 17 & 2.225 \\
\hline 19 & 110 & 40 & 20 & 2.3103 & 8 & 18.4824 & 2.288 \\
\hline 20 & 110 & 40 & 20 & 2.3103 & 8 & 18.4824 & 2.288 \\
\hline
\end{tabular}

\section{RESULTS AND DISCUSSION}

A. Optimum parameters using Taguchi's analysis

Figures2 and 3 show graphically the effect of three process parameters on MRR and Ra respectively. The response tables for $\mathrm{S} / \mathrm{N}$ ratio of MRR and Ra are shown in Tables 6 and 7 respectively. Using MINITAB 16, analysis was made followed by generation of response tables and main effect plots. Based on the analysis, results obtained are: factors at levels $\mathrm{T}_{\mathrm{ON}}=115 \mu \mathrm{s}$ 
(Level 3), $\mathrm{T}_{\mathrm{OFF}}=30 \mu \mathrm{s}$ (Level 1) and $\mathrm{SV}=20 \mathrm{~V}$ (Level 2), which results in maximum MRR and similarly factors at level $\mathrm{T}_{\mathrm{ON}}$ $=105 \mu \mathrm{s}$ (Level 1), $\mathrm{T}_{\mathrm{OFF}}=50 \mu \mathrm{s}$ (Level 3) and $\mathrm{SV}=25 \mathrm{~V}$ (Level 3) which results in minimum Ra.

Table 6 : Response table for $\mathrm{S} / \mathrm{N}$ ratio of MRR

\begin{tabular}{|c|c|c|c|}
\hline Level & $\mathrm{T}_{\text {ON }}$ & $\mathrm{T}_{\text {OFF }}$ & $\mathrm{SV}$ \\
\hline 1 & 20.17 & $\mathbf{2 6 . 1 5}$ & 24.11 \\
\hline 2 & 24.11 & 25.39 & $\mathbf{2 4 . 3 0}$ \\
\hline 3 & $\mathbf{2 6 . 8 9}$ & 19.69 & 22.77 \\
\hline Delta & 6.72 & 6.52 & 1.53 \\
\hline Rank & 1 & 2 & 3 \\
\hline
\end{tabular}

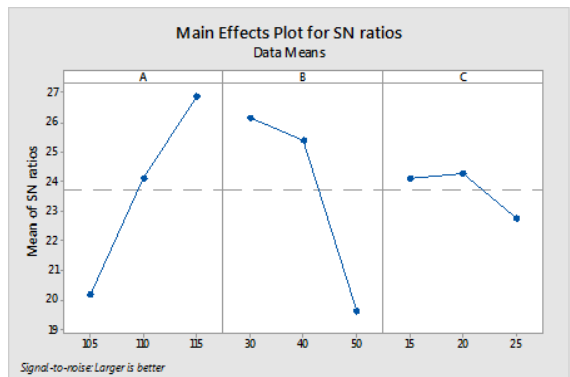

Figure 2: Main effects plot for S/N ratio of MRR
Table 7 Response table for $\mathrm{S} / \mathrm{N}$ ratio of $\mathrm{Ra}$

\begin{tabular}{|c|c|c|c|}
\hline Level & $\mathrm{T}_{\mathrm{ON}}$ & $\mathrm{T}_{\mathrm{OFF}}$ & $\mathrm{SV}$ \\
\hline 1 & $\mathbf{- 5 . 2 9 1}$ & 6.850 & 7.134 \\
\hline 2 & 6.894 & 6.720 & 6.127 \\
\hline 3 & 7.026 & $\mathbf{5 . 6 4 0}$ & $\mathbf{5 . 9 5 0}$ \\
\hline Delta & 1.735 & 1.210 & 1.184 \\
\hline Rank & 1 & 2 & 3 \\
\hline
\end{tabular}

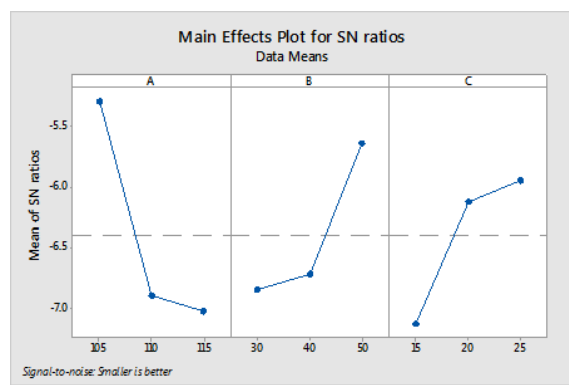

Figure 3 : Main effects plot for $\mathrm{S} / \mathrm{N}$ ratios of $\mathrm{Ra}$

\section{B. Confirmation experiment for results obtained from Taguchi}

The optimal combination of process parameter obtained from analysis of results are verified by conducting the experiments for those combinations and compared with the value predicted by using equation 7 for MRR and Ra separately. Both experimental and predicted values for optimum parameter to get maximum MRR and minimum Ra are shown in Table 8 and Table 9 respectively.

$\hat{n}=n_{m}+\sum_{i=1}^{p}\left(\overline{n_{1}}-n_{m}\right)$

Where $n_{m}=$ Total mean of $\mathrm{S} / \mathrm{N}$ ratio, $\bar{n}_{\mathrm{v}}=$ Mean of $\mathrm{S} / \mathrm{N}$ ratio at optimum level of each parameter $\mathrm{p}=$ Number of main machining parameters (Here 3)

Table 8 Confirmation experiment for MRR

Table 9 Confirmation experiment for Ra

\begin{tabular}{|c|c|c|}
\hline \multicolumn{3}{|c|}{ Optimal machining parameter } \\
\hline & Prediction & Experimental \\
\hline Level & $\begin{array}{c}\mathrm{T}_{\text {ON }} 3, \mathrm{~T}_{\text {OFF }} 1, \\
\text { SV 2 }\end{array}$ & $\begin{array}{c}\mathrm{T}_{\text {ON }} 3, \mathrm{~T}_{\text {OFF }} 1, \\
\text { SV 2 }\end{array}$ \\
\hline $\begin{array}{c}\text { S/N Ratio for } \\
\text { MRR }\end{array}$ & 29.8856 & 29.5192 \\
\hline MRR & 31.2197 & 29.92 \\
\hline \% error & \multicolumn{2}{|c|}{$4.34 \%$} \\
\hline
\end{tabular}

\begin{tabular}{|c|c|c|}
\hline \multicolumn{3}{|c|}{ Optimal machining parameter } \\
\hline & Prediction & Experimental \\
\hline Level & $\begin{array}{c}\mathrm{T}_{\mathrm{ON}} 1, \mathrm{~T}_{\mathrm{OFF}} 3, \\
\text { SV } 3\end{array}$ & $\begin{array}{c}\mathrm{T}_{\mathrm{ON}} 1, \mathrm{~T}_{\mathrm{OFF}} 3, \\
\mathrm{SV} 3\end{array}$ \\
\hline $\begin{array}{c}\text { S/N Ratio for } \\
\text { Ra }\end{array}$ & -4.074 & -4.2063 \\
\hline $\mathrm{Ra}$ & 1.5984 & 1.623 \\
\hline$\%$ error & & \\
\hline
\end{tabular}

C. Optimum parameters using Response Surface Methodology (RSM)

Based on Analysis of Variance (ANOVA) Figures 4 and 5 show the effect of three process parameters on MRR and Ra respectively, indicating that $\mathrm{T}_{\mathrm{ON}}$ is the most affecting parameter for both MRR and Ra, while pulse off time and Servo voltage are less significant for both MRR and Ra.

Figures 6 and 7 show optimization plot using desirability approach for MRR and Ra respectively. Main effect plots, optimization plots and surface plots are generated using MINITAB 16.

Desirability approach has been used for finding out the optimum values of the process parameter in order to get the maximum value of MRR and minimum value of Ra. It is clear from the Figure 6 that highest value of $\mathrm{MRR} 31.4975 \mathrm{~mm} / \mathrm{min}$, is obtained for the combination of Ton $=115 \mu \mathrm{s}, \mathrm{T}_{\mathrm{OFF}}=30 \mu \mathrm{s}$ and $\mathrm{SV}=15$ volt. It is clear from the Figure 7 that lowest value of $\mathrm{Ra} 1.6228 \mu \mathrm{m}$ is obtained for the combination of Ton $=105 \mu \mathrm{s}, \mathrm{T}_{\mathrm{OFF}}=50 \mu \mathrm{s}$ and $\mathrm{SV}=25$ volt. The results obtained are with the composite desirability of 1.000 . 


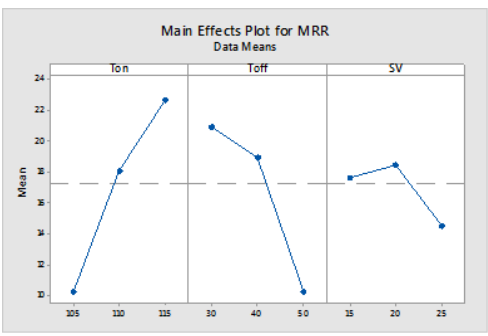

Figure 4: main effects plot for data means of MRR

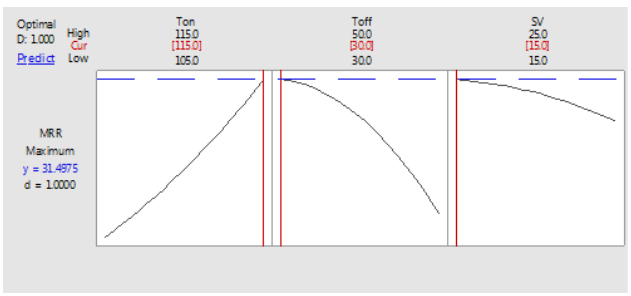

Figure 6: Optimization plot for MRR

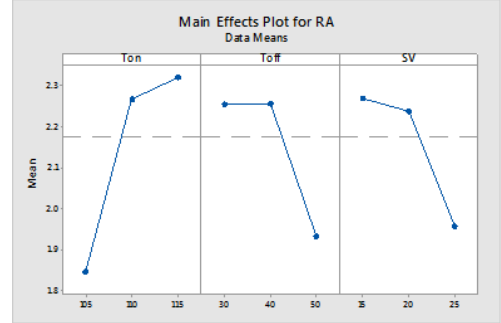

Figure 5: main effects plot for data means of $R a$

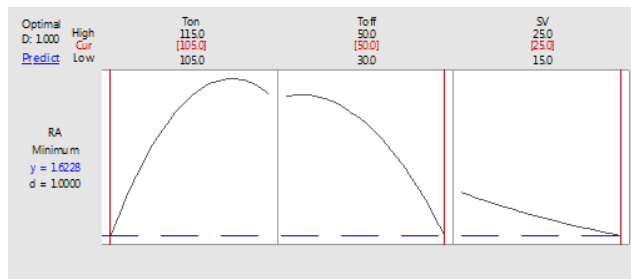

Figure 7: Optimization plot for Ra

D. Confirmation experiments for results obtained from RSM

The optimal combinations obtained from the analysis of results are verified by conducting the experiments for those combinations. The mathematical model expressing the relation between process parameters and performance parameters (MRR and Ra) was generated using MINITAB 16. This equation called as regression equation was used to predict the performance parameter value for the optimal combinations. Both experimental and predicted values for optimum parameters to get maximum MRR and minimum Ra are shown in Table 10.

For MRR and Ra, regression equation are given in equation 8 and 9 respectively

$$
\begin{aligned}
\text { MRR }= & 191-6.95 \text { Ton }+6.18 \text { Toff }+3.15 \mathrm{SV}+0.0461 \text { Ton*Ton }-0.03236 \text { Toff*Toff } \\
& -0.0318 \mathrm{SV} * \mathrm{SV}-0.0382 \text { Ton*Toff }-0.0213 \text { Ton*SV }+0.0038 \text { Toff*SV }
\end{aligned}
$$

$\mathrm{Ra}=-77.3+1.332$ Ton +0.0423 Toff $+0.353 \mathrm{SV}-0.00551$ Ton*Ton -0.000882 Toff*Toff

$$
+0.00025 \mathrm{SV} * \mathrm{SV}+0.000042 \text { Ton*Toff }-0.00373 \mathrm{Ton} * \mathrm{SV}+0.000378 \text { Toff*SV }
$$

\begin{tabular}{|c|c|c|c|c|c|c|c|c|c|c|c|}
\hline \multirow{3}{*}{$\begin{array}{l}\text { Resp } \\
\text { onse }\end{array}$} & \multirow{2}{*}{\multicolumn{3}{|c|}{$\begin{array}{l}\text { Optimized value of } \\
\text { input parameter }\end{array}$}} & \multirow{3}{*}{$\begin{array}{l}\text { Predict } \\
\text { ed }\end{array}$} & \multirow{3}{*}{$\begin{array}{c}\text { Expe } \\
\text { rime } \\
\text { ntal }\end{array}$} & \multirow{3}{*}{$\begin{array}{c}\% \\
\text { Error }\end{array}$} & \multirow{3}{*}{$\begin{array}{c}\text { Respo } \\
\text { nse }\end{array}$} & \multicolumn{4}{|c|}{ Experimental results } \\
\hline & & & & & & & & $\mathrm{Taq}$ & chi's & $\mathrm{RS}$ & \\
\hline & $\mathrm{T}_{\mathrm{ON}}$ & $\mathrm{T}_{\mathrm{OFF}}$ & $\mathrm{V}$ & & & & & $\begin{array}{l}\text { Experi } \\
\text { mental }\end{array}$ & $\begin{array}{c}\text { predicte } \\
\mathrm{d}\end{array}$ & $\begin{array}{l}\text { Experim } \\
\text { ental }\end{array}$ & $\begin{array}{c}\text { Predict } \\
\text { ed }\end{array}$ \\
\hline $\mathrm{M}$ & 115 & 30 & 15 & & & 4.4 & & .92 & 31.2197 & & 31.497 \\
\hline $\mathrm{Ra}$ & 05 & 50 & שE & 1.6228 & 1.623 & 0.0123 & $\mathrm{Ra}$ & 1.623 & 1.5984 & 1.623 & 1.6228 \\
\hline
\end{tabular}

Table 10: Confirmation experiments for MRR and Ra Table 11: Comparison of results of RSM and Taguchi 


\section{E. Comparison of Taguchi technique and RSM}

Experimental and predicted results for both Taguchi's and RSM techniques based on optimal parameter combination is shown in Table 11. Also it was observed that different optimum parameter combination is obtained from Taguchi and RSM for MRR, while same combinations obtained for Ra. It can be observed from the Table 11 that the MRR and Ra values obtained from both techniques are very close to each other.

\section{CONCLUSIONS}

In this study an attempt was made to determine the values of optimum process parameter to maximize the material removal rate and minimize the surface roughness in Wire EDM. Both RSM and Taguchi techniques are applied for optimization. From the above work it can be concluded that

- $\quad$ Both techniques have revealed comparable results.

- The results obtained from both RSM and Taguchi techniques are very close for the considered combination of optimal of process parameters.

- Though the optimal process parameters combinations for maximization of MRR are different from RSM and Taguchi technique, the MRR obtained is close to each other.

- Optimal process parameter combinations for minimization of Ra are same from RSM and Taguchi technique and results are close to each other.

- As the time and experimental trials required by RSM is much more than that of Taguchi method also results obtained from both methods are very close, the Taguchi technique (L9) is more suitable than RSM (L20) for optimization of parameters of HSS material in the chosen experimentation.

- It is clear that Pulse on time has greater influence on maximization of MRR and minimization of Ra. Also, pulse off time and servo voltage influence the MRR and Ra to a smaller extent.

- $\quad$ Customized values of MRR and Ra can be obtained by solving equation obtained from desirability approach.

\section{REFERENCES}

[1] S. S. Mahapatra\& Amar Patnaik (2006), Optimization of wire electrical discharge Machining (WEDM) process parameters using Taguchi method, J. of the Braz. Soc. Of Mech. Sci. \& Eng. Vol. 28, No. pp-422-429

[2] PragyaShandilyaa*, P.K.Jainb N.K. Jain (2012), Parametric optimization during wire electrical discharge machining using response surface methodology, Procedia Engineering 38, pp 2371-2377

[3] R.Pandithurai, I. Ambrose Edward (2014), Optimizing surface roughness in Wire-EDM using machining parameters, International Journal of Innovative Reaserch in Science, Engineering and Technology, vol. 3, Special issue 3, pp 1321-1324

[4] G. Venkateswarlu, P. Devaraj (2015), Optimization of Machining Parameters in Wire EDM of Copper Using Taguchi Analysis, International Journal of Advanced Materials Research Vol. 1, No. 4, 2015, pp. 126-131

[5] Vikram Singh, S.K, Pradhan (2014), Optimization of WEDM parameters using Taguchi technique and Response Surface Methodology in machining of AISI D2 Steel, Procedia Engineering 97, pp 1597-1608

[6] Pratik A. Patil, C.A. Waghmare, Optimization of process parameters in Wire EDM using RSM, Proceedings of $10^{\text {th }}$ International Conference, pune, India, ISBN: 978-93-84209-23-0

[7] K. Kumar, R Ravikumar (2013), Modelling and Optimization of Wire EDM process, International Journal of Madern Engineering Research, Vol. 3, Issue. 3, pp-1645-1648.

[8] Neeraj Sharma, Rajesh Khanna, Rahul Dev Gupta (2015), WEDM process variables investigation for HSLA by response surface methodology and genetic algorithm, Engineering Science and Technology, an International Journal 18, pp 171-177

[9] Singaram Lakshmanan, Mahesh Kumar (2013), Optimization of EDM parameters using Response Surface Methodology for EN31 Tool Steel Machining, International Journal of Engineering Science and Innovative Technology, Vol. 2, Issue 5, pp 64-71 